\title{
DIREITOS DOS ANIMAIS E A PROBLEMÁTICA DA EFETIVIDADE DA NORMA CONSTITUCIONAL
}

\section{DERECHOS DE LOS ANIMALES Y EL PROBLEMA DE LA EFICACIA DE LA NORMA CONSTITUCIONAL}

\section{${ }^{1}$ Suelen de Souza Fernandes}

\section{RESUMO}

O presente estudo tem o propósito de abordar o cenário geral das normas brasileiras, em sua raiz antropocêntrica, que regulam a relação entre homens e animais não humanos; a não efetividade do texto constitucional quanto à proteção desses animais, bem como a discussão sobre seu posicionamento dentro do ordenamento jurídico brasileiro. Buscar-se-ão na biologia e na filosofia argumentos que sustentem o reconhecimento de direitos aos animais para, assim, reconstruir sua definição para o Direito. Analisar-se-á ainda o tratamento dispensado hoje aos animais não humanos no direito comparado e a dignidade inerente a esses animais por serem detentores de dignidade.

Palavras-chave: Dignidade, Direitos, Animais não humanos, Efetividade, Norma constitucional

\section{RESUMEN}

Este estudio tiene como objetivo indicar la situación general de los estándares brasileños, en su raíz antropocéntrica, que regulan la relación entre humanos y animales no humanos; la ineficacia de la Constitución para la protección de estos animales y su tratamiento dentro del sistema jurídico brasileño. Se buscarán en biología y filosofía argumentos para apoyar el reconocimiento de los derechos de los animales, de este modo reconstruir su definición a la ley. Se examinará el tratamiento actual a los animales no humanos en el derecho comparado y de la dignidad inherente a estos animales para ser titulares de dignidad.

Palabras-claves: Dignidad, Derechos, Animales no humanos, Efectividad, Norma constitucional

\footnotetext{
${ }^{1}$ Graduada em Direito pela Universidade Gama Filho - UGF, Rio de Janeiro - RJ (Brasil).

E-mail: fernandes_su@yahoo.com.br
} 


\section{INTRODUÇÃO}

É sabido que a sociedade vive em constante transformação e considerando que o Direito é o reflexo do homem na sociedade, não pode em absoluto o Direito tornar-se algo estático. Dessa forma, faz-se necessária uma nova visão quanto a determinados direitos através da reconstrução de conceitos.

Partindo do pressuposto que o Direito é um fenômeno social, a metodologia a ser utilizada partirá de ensinamentos e experiências vividas por estudiosos para, posteriormente, se adentrar ao campo jurídico. A pesquisa científica no âmbito do Direito é complexa no sentido que a transformação social constante vivenciada e as diversas formas de se interpretar e construir o conhecimento.

Percebe-se uma revolução hermenêutica da sociedade dos dias atuais no que tange à relação entre o Direito e os animais não humanos. Baseado em uma teoria kantiana, o Direito observava os animais como coisas e máquinas, que serviam como objetos nas mãos do homem. Tal visão foi influenciada pela igreja que propagava o pensamento de que apenas o homem possuía alma.

A desconstrução desse pensamento somente veio no final do século XVIII com a proteção ao animal não humano, ocupando um espaço maior na esfera da filosofia. Em 1789, Jeremy Bentham, filósofo e jurista britânico, publica o livro Introduction to Principles of Morals and Legislation ${ }^{1}$. O filósofo Peter Singer, autor da obra Libertação Animal ${ }^{2}$, propôs uma nova visão com o princípio moral básico da igual consideração de interesses, que protege a igualdade de todos os seres humanos com suas respectivas diferenças.

Em que pese a inovação hermenêutica trazida ao ordenamento jurídico, com a consideração moral aos animais não humanos, ainda hoje o ordenamento jurídico brasileiro dispensa aos animais o tratamento de "bens móveis", o contrário se observa no direito comparado, que inovou a natureza jurídica dos animais não humanos como sujeitos de direito.

O sistema constitucional brasileiro priorizou a função ecológica da fauna e não tratou individualmente os animais não humanos. Vive-se ainda o problema da não efetividade da

\footnotetext{
${ }^{1}$ BENTHAM, Jeremy; MILL, John Stuart. An introduction to the principles of morals and legislation. New York, NY: Dolphin Books, 1961.

2 SINGER, Peter. Libertação Animal. Trad. Marly Winckler, Marcelo Brandão Cipolla, São Paulo: Martins Fontes, 2013.
} 
norma constitucional no que se refere a esses animais, vez que as normas infraconstitucionais mitigam a proteção prevista no $\S 1^{\circ}$, VII do artigo 225 da Constituição Federal.

O objetivo central desse artigo é a busca pela efetivação das regras contidas no texto constitucional quanto à responsabilidade do poder público na proteção dos animais não humanos.

A relevância desse trabalho está inserida na efetivação do reconhecimento de dignidade e valor intrínseco aos animais não humanos, seguindo o mesmo ideal dos países Áustria, Alemanha e Suíça.

\section{A PROBLEMÁTICA DA CONCRETIZAÇÃO DO DIREITO}

Sabe-se que o Estado Democrático de Direito, caracterizado como um verdadeiro Estado Constitucional, está intimamente ligado à efetivação dos direitos fundamentais.

Nos últimos 20 anos, não se conseguiu construir uma nova teoria das fontes, continua-se a utilizar os velhos pressupostos. A jurisdição constitucional não é sinônimo de apoderamento do direito pelo poder judiciário. O Brasil adotou teorias de valores e argumentação jurídica que, na prática, acaba-se criando um Estado de natureza hermenêutica em que o poder judiciário, ao fazer uso de sua discricionariedade, passa, muitas vezes, dos limites semânticos previstos no próprio texto constitucional. Em outras palavras, em um Estado democrático de direito, em que se aumenta a jurisdição constitucional, diminui-se, todavia, o espaço do legislador.

Para melhor compreensão dessa problemática, faz-se necessário discutir o papel do direito e a justiça constitucional no Estado Democrático de Direito. Para se entender o constitucionalismo contemporâneo, compreendido como o constitucionalismo do Estado Democrático de Direito, salienta-se a compreensão da relação entre Constituição e Jurisdição Constitucional. Por um lado, tem-se a Constituição como fundamento de validade superior do ordenamento e consubstanciadora da própria atividade político-estatal. Por outro lado, a Jurisdição Constitucional passa a ser a condição de possibilidade do Estado Democrático de Direito $^{3}$. Do que se extrai, percebe-se que o significado de Constituição está intimamente ligado à hermenêutica do conteúdo contido no tex to constitucional.

\footnotetext{
${ }^{3}$ Streck, Lênio Luiz. Jurisdição Constitucional e Hermenêutica - Uma nova crítica do Direito. Rio de Janeiro: Forense, 2004, p. 13.
} 
O Brasil ainda enfrenta a problemática da implementação dos principais componentes do Estado Democrático de Direito advindos da Constituição de 88. Não se abriu mão dos velhos paradigmas de direito, o que acarreta desvios na compreensão da Constituição e do papel da jurisdição constitucional. Nas palavras do ilustre professor Lênio Streck ${ }^{4}$ :

\begin{abstract}
Antigas teorias acerca da Constituição e da legislação ainda povoam o imaginário dos juristas, A partir da divisão entre "jurisdição constitucional" e jurisdição ordinária", entre "constitucionalidade" e "legalidade", como se fossem mundos distintos, separados metafisicamente, a partir do esquecimento daquilo que Heidegger chamou de diferença ontológica. Essa separação metafísica denuncia, em certa medida, o modelo frágil de jurisdição constitucional que praticamos no Brasil, o que inexoravelmente redunda em um conceito frágil acerca da Constituição, fenômeno que não é difícil de constatar a partir de uma análise acerca do grau de (in)efetividade do texto constitucional em vigor.
\end{abstract}

Quase duas décadas se passaram desde a promulgação da Constituição e a população ainda se depara com o problema da ineficácia de parte do texto constitucional e com obstáculos quanto à sua efetividade. Sabe-se hoje que o texto constitucional por si só não traz garantias de efetividade de suas normas, tampouco cumpre com seu ideário inicial. Logo, devido a esse modelo existente, explica-se a importância da atuação dos juristas e do poder judiciário na medida em que uma Constituição rica em direitos padece de resultados práticos. Nesse raciocínio, o Direito deve ser visto como a área de realização das promessas modernas contidas na Carta Magna de 88 e não servir como mera lógica instrumental.

É notório que o Brasil enfrenta um grave problema quanto à aplicação da lei, tendo em vista o modelo de Direito hoje aplicado ser o liberal-indivualista, o que contribui para essa desfuncionalidade entre o Direito e as instituições encarregadas de aplicar a lei. "Há um certo fascínio pelo Direito infraconstitucional, a ponto de se "adaptar" a Constituição às leis ordinárias... Enfim, continuamos a olhar o novo com os olhos do velho... „5.

A Revolução Copernicana trouxe mudanças significativas ao Direito Público com a transição de uma fase em que as normas constitucionais eram submetidas ao interpositio legislatoris, para uma fase em que tais normas são suscetíveis de aplicação direta. Resulta-se, assim, no surgimento de uma justiça constitucional.

A Constituição brasileira concentra uma gama de valores e possui um caráter compromissário com mecanismos de implementação das políticas do Welfare State. Assim,

\footnotetext{
${ }^{4}$ Streck, Lênio Luiz. Jurisdição Constitucional e Hermenêutica - Uma nova crítica do Direito. Rio de Janeiro: Forense, 2004, p. 14.

${ }^{5}$ Streck, Lênio Luiz. Jurisdição Constitucional e Hermenêutica - Uma nova crítica do Direito. Rio de Janeiro: Forense, 2004, p. 17.
} 
considerando o caráter compromissário do texto constitucional e a força normativa da Constituição, visualiza-se, muitas vezes, o deslocamento das funções pertencentes aos poderes legislativo e executivo para as mãos do poder judiciário, ante a inércia daqueles poderes, através de mecanismos jurídicos disponibilizados na Constituição.

No paradigma liberal, a função do Direito era ordenadora. Já no Estado Democrático de Direito, a função do Direito é transformadora, em que se verifica a atuação direta do poder judiciário na concretização do Direito. O papel do Direito e da Justiça constitucional é analisado de acordo com cada país especificamente. Há que se superar a crise de paradigma liberal-individualista que, ante o novo modelo Estado Democrático de Direito, dificulta o aparecimento da Constituição.

Com as novas prerrogativas de cunho constitucional, um novo olhar para a ordem constitucional surge. Uma nova leitura dos direitos fundamentais é realizada e se redefinem os conceitos de liberdade e igualdade.

O direito ambiental, por exemplo, embora discutido por décadas, sofre com a ausência de efetividade da norma. O meio ambiente é um direito fundamental de terceira geração, cujo titular é a própria coletividade ${ }^{6}$. Tanto o legislador quanto o aplicador do direito têm o dever de tornar efetiva a norma constitucional. Tem-se o meio ambiente como um bem jurídico passível de tutela jurisdicional, visto hoje como uma nova dimensão de direito fundamental.

O Estado Democrático de Direito é a garantia e efetivação dos direitos fundamentais. Os direitos e garantias fundamentais fundamentam-se na dignidade da pessoa humana, logo a proteção ao meio ambiente é voltada para o desfrute e deleite do próprio homem para se atingir uma vida digna.

No capítulo do meio ambiente, a Constituição Federal no art. 225, § 1º, VII, dispôs sobre a proteção da fauna, vedada as práticas que coloquem as espécies em extinção e que submetam os animais à crueldade. Em que pese o antropocentrismo apresentado no caput do art. 225 da Constituição Federal, observa-se um equilíbrio, nos incisos e parágrafos do artigo acima apontado, com o biocentrismo. O meio ambiente ecologicamente equilibrado só seria possível com a harmonia entre os seres vivos e o meio ambiente em que se encontram inseridos.

\footnotetext{
${ }^{6}$ CANOTILHO, José Joaquim. O direito ao ambiente como direito subjectivo. In: A tutela jurídica do meio ambiente: presente e futuro. Boletim da Faculdade de Direito da Universidade de Coimbra - Stvdia Ivridica 81, Colloquia 13. Coimbra: Coimbra Editora, 2005. p.49.
} 
O direito dos animais ganha amparo no ordenamento jurídico constitucional a partir do art. 225 da Constituição Federal. Ocorre, todavia, que a proteção legislativa constitucional, no que se refere ao direito dos animais, é mitigada por normas infraconstitucionais, que ignoram o disposto no mandamento previsto na Lei Maior.

\subsection{Fundamentos de um Direito Animal Constitucional}

Os princípios democráticos reconhecem a felicidade individual e a justiça equitativa como bens protegidos constitucionalmente. Consideram-se o bem-estar ambiental e social essenciais para a felicidade do indivíduo.

As constituições democráticas estabelecem normas de coação para fins de se evitar que determinadas ações destruam a integridade ambiental, social e emocional dos membros integrantes de uma comunidade. Diferenças biológicas, religiosas ou étnicas não autorizam a distribuição de bens sem os critérios da equidade, dessa forma, se tutela constitucionalmente todos aqueles que possuam valor intrínseco, ainda que alguns integrantes sejam vistos como meras coisas vivas (animais não humanos e elementos físicos da natureza). Nessa linha de raciocínio, entende-se por prática inconstitucional a destruição de elementos naturais e o extermínio da diversidade de espécies vivas.

O reconhecimento de direitos à natureza em geral, e em especial aos animais, tem sido objeto de discussão na doutrina brasileira e mundial. Destaque-se que a referência clássica, baseada em Kant, no que diz respeito aos deveres dos seres humanos em relação aos animais, um dever de tutela, abrange exclusivamente o interesse antropocêntrico. Kant observou o mundo sob dois conceitos sociais, um ligado ao preço das coisas e outro ligado à moral. O homem, ser racional e autônomo, detentor de dignidade e valor intrínseco, deve ser tratado como fim em si mesmo e nunca como meio para uma determinada ação, já as coisas têm preço e valor instrumental. Hobbes, em sua obra o Leviata ${ }^{7}$, afirma que o Estado atribui valor real ao homem. A dignidade humana está relacionada àquilo que o homem faz e a sociedade política reconhece. Descartes ${ }^{8}$, no século XVI, sustentou a teoria mecanicista, a qual fortalecia a ideia de que o animal não humano seria máquina, logo, justificável sua exploração. Para Descartes, os animais não possuíam alma, não falam e muito menos sentem dor. Os animais são autômatos, logo, justificável é a sua exploração, pois se tratam de seres destituídos de sentimentos, incapazes de conhecer a dor e prazer.

\footnotetext{
7 HOBBES, Thomas. Leviatã. Trad. Rosina D’Angina. São Paulo: Martin Claret, 2015, pg. 82.

8 DESCARTES, René. Discurso do método. Trad. de Paulo Neves, Porto Alegre: L\&PM pocket, 2015, p. 37-38.
} 
Para o pensamento filosófico e político da antiguidade clássica, o vocábulo dignidade era voltado à espécie humana. Digno, portanto, era o ocupante de determinada posição social e reconhecido pelos demais membros de uma sociedade. A ideia de valor intrínseco (dignidade) inerente ao homem tem raízes no pensamento clássico e no ideário cristão. Do ponto de vista cristão, tanto no antigo quanto no novo testamento, partindo da máxima de que o homem foi criado à imagem e à semelhança de Deus, tem-se que o ser humano possui um valor intrínseco próprio, o que rechaça qualquer concepção que lhe venha reduzir ao status de coisa ou objeto.

Em contrapartida, o movimento da libertação animal, também chamado de movimento revisionista, está voltado à vida em um amplo sentido, tendo em vista seu caráter revisor pautado na quebra de paradigma entre o antropocentrismo e o biocentrismo. Amplia-se, por conseguinte, os membros da comunidade moral com a inclusão não apenas dos seres humanos como também dos não humanos e da natureza. Verifica-se, assim, a possibilidade de se reconhecer a dignidade como atributo inerente a outras formas de vidas não humanas. Quando se legisla contra a crueldade aos animais, a proteção encontra-se no animal como ser em si mesmo, já que possui valor intrínseco e é detentor de dignidade.

A Constituição Federal brasileira, em seu art. $225, \S 1^{\circ}$, VII ${ }^{9}$, enuncia que incumbe ao poder público a proteção da fauna e da flora, bem como a proteção quanto às práticas que submetam os animais à crueldade, evidenciando o reconhecimento de valor intrínseco a outras formas de vida.

No ordenamento jurídico infraconstitucional, verifica-se a proteção animal, sob a ótica do direito penal, com a criminalização de condutas humanas que acarretem crueldade e maus-tratos contra animais. No âmbito da legislação ambiental (lei $n^{\circ}$ 9.605/98), na seção dos crimes contra fauna, reconhece-se valor à vida animal, quando se criminaliza a conduta humana em relação a atos decorrentes de abuso ou maus-tratos. O tipo penal do caput do art. 32 da Lei $n^{\circ} 9.605 / 98^{10}$ estende-se àqueles que realizam experiências dolorosas ou cruéis em animais vivos, ainda que para fins didáticos ou científicos, quando houver métodos alternativos.

\footnotetext{
${ }^{9}$ Brasil. Constituição da República Federativa do Brasil. Diário Oficial da União, Brasília, DF, 05 out. 1988. Disponível em: http://www.planalto.gov.br/ccivil_03/Constituicao/Constituicao.htm. Acesso em: 01/11/2015.

${ }^{10}$ BRASIL. Lei $\mathrm{n}^{\circ}$ 9.605/98, de 12 de fevereiro de 1998. Diário Oficial da República Federativa do Brasil. Brasília, DF, 13 fev. 1998. Disponível em: < http://www.planalto.gov.br/ccivil_03/LEIS/L9605.htm>. Acesso em: 10/11/2015.
} 
A jurisprudência brasileira vem decidindo, com amparo do STF, a favor da vedação de práticas cruéis contra a vida animal. O Supremo Tribunal Federal decidiu pela inconstitucionalidade da prática da farra do boi ${ }^{11}$, em Santa Catarina; e, no Rio de Janeiro, pela inconstitucionalidade da lei que regulamentava a briga de galo ${ }^{12}$, com base no art. 225 , $\S 1^{\circ}, \mathrm{CR} / 88$.

A lei de $\operatorname{rodeios}^{13}$ (lei $\left.n^{\circ} 10.519 / 02\right)$ permite a realização de rodeios, porém com restrições a alguns equipamentos, com o objetivo de causar menos dor ao animal. Nesse caso, o direito ao lazer prevaleceu ante a vida do animal não humano. As adaptações feitas à lei de rodeio têm a finalidade de afastá-la da incidência da tipificação do art. 32 da lei de crimes ambientais.

A prática da vivissecção, prevista na lei n ${ }^{\circ} 11.794 / 98^{14}$, é permitida no Brasil e tem por finalidade a experimentação em animais vivos. Aqui, a tolerância à crueldade se dá em nome da ciência. O parágrafo único do art. 32 da lei dos crimes ambientais ${ }^{15}$ conferiu limites à vivissecção quando existirem métodos alternativos.

A lei de “proteção" à fauna (lei no $5197 / 67^{16}$ ) proíbe a utilização, perseguição, destruição ou caça de animais que constituam a fauna silvestre, bem como o exercício da caça profissional. Porém, o parágrafo primeiro do art. $1^{\circ}$ do mesmo diploma legal mitiga tal proteção e permite, através de ato regulamentador do poder público federal, tais práticas

11 BRASIL. Supremo Tribunal Federal. Recurso Extraordinário n. 153531. STF, RE 153531, Rel. Min. FRANCISCO REZEK, Relator(a) p/ Acórdão: Min. MARCO AURÉLIO, Segunda Turma, julgado em 03/06/1997, DJ 13-03-1998 PP-00013 EMENT VOL-01902-02 PP-00388). Disponível em: http://www.stf.jus.br/portal/jurisprudencia/listarJurisprudencia.asp?s1=\%28RE+153531\%29\&base=baseAcordao s. Acesso em: 30/11/2015.

${ }^{12}$ BRASIL. Supremo Tribunal Federal. ADI n. 1856. STF, ADI 1856, Rel. Min. CELSO DE MELLO, Tribunal Pleno, julgado em 26/05/2011, DJe-198 DIVULG 13-10-2011 PUBLIC 14-10-2011 EMENT VOL-02607-02 PP-00275 RTJ VOL-00220- PP-00018 RT v. 101, n. 915, 2012, p. 379-413. Disponível em: < http://www.stf.jus.br/portal/jurisprudencia/listarJurisprudencia.asp?s1=\%28ADI+1856\%29\&base=baseAcordaos >. Acesso em: 30/11/2015.

${ }^{13}$ BRASIL. Lei $n^{\circ}$ 10.519/02, de 17 de julho de 2002. Diário Oficial da República Federativa do Brasil. Brasília, DF, 18 jul. 2002. Disponível em: < http://www.planalto.gov.br/ccivil_03/leis/2002/L10519.htm>. Acesso em: $02 / 11 / 2015$.

${ }^{14}$ BRASIL. Lei $\mathrm{n}^{\circ}$ 11.794/98, de 08 de outubro de 2008. Diário Oficial da República Federativa do Brasil. Brasília, DF, 09 out. 2008. Disponível em: < http://www.planalto.gov.br/ccivil_03/_ato20072010/2008/lei/111794.htm>. Acesso em: 02/11/2015.

${ }^{15}$ BRASIL. Lei $\mathrm{n}^{\circ}$ 9.605/98, de 12 de fevereiro de 1998. Diário Oficial da República Federativa do Brasil. Brasília, DF, 13 fev. 1998. Disponível em: < http://www.planalto.gov.br/ccivil 03/LEIS/L9605.htm>. Acesso em: 02/11/2015.

${ }^{16}$ BRASIL. Lei no 5.197/67, de 03 de janeiro de 1967. Diário Oficial da República Federativa do Brasil. Brasília, DF, 03 jan. 1967. Disponível em: 〈http://www.planalto.gov.br/ccivil 03/LEIS/L5197.htm〉. Acesso em: $02 / 11 / 2015$. 
quando as peculiaridades regionais comportarem a caça. A lei gaúcha $\mathrm{n}^{\mathrm{o}} 10.056 / 94^{17}$ permite a caça amadora e se encontra amparada na brecha constante $\S 1^{\circ}$, art. $1^{\circ}$ da lei acima mencionada.

A sociedade é dinâmica e vive em constante transformação social e de conceitos. O Direito, não podia ser diferente, pois decorre de tais transformações. A Constituição Federal de 88 posiciona os animais não humanos como beneficiários de direitos dentro do sistema constitucional, garantindo-lhes a proteção à crueldade e, com isso, reconhece um valor intrínseco ao animal não humano. Ocorre, contudo, que o sistema brasileiro ainda é limitado aos interesses antropocêntricos e baseado em tradições arcaicas.

\subsection{O Antropocentrismo Normativo}

A Declaração Universal dos Direito Humanos de $1948^{18}$, avanço fundamental para a humanidade, foi o primeiro documento que fixou direitos internacionalmente tanto para homens quanto para mulheres, sem distinção de raça, faixa etária ou classe social. A dignidade humana tem por base os direitos reconhecidos ao longo da história, o que insere o homem em determinada comunidade política, em que assume deveres e obrigações.

Hoje, há um complexo de normas escritas e codificadas que formam o direito objetivo, que tem por finalidade gerenciar as relações sociais de natureza humana. O preâmbulo da Constituição Federal de 88, tal como exposto, pode ser encontrado em diversas constituições chamadas democráticas. Contempla única e exclusivamente o interesse dos seres humanos vistos, em um ideal democrático, como cidadãos dotados de autonomia e razão. Tão somente aos seres humanos são conferidos os seguintes direitos: “... a liberdade, a segurança, o bemestar, o desenvolvimento, a igualdade e a justiça como valores supremos de uma sociedade fraterna, pluralista e sem preconceitos, fundada na harmonia social e comprometida, na ordem interna e internacional..." ${ }^{\prime 19}$. Pelo o que se observa, as democracias

\footnotetext{
${ }^{17}$ BRASIL. Lei no 10.056/94, de janeiro de 1994. Diário Oficial da República Federativa do Brasil. Porto Alegre, POA, 10 jan. $1994 . \quad$ Disponível em: http://www.al.rs.gov.br/legis/M010/M0100099.ASP?Hid_Tipo=TEXTO\&Hid_TodasNormas=13809\&hTexto= \&Hid_IDNorma=13809. Acesso em: 02/11/2015.

${ }^{18}$ ONU. Resolução 217 A (III) da Assembleia Geral das Nações Unidas, de 10 de dezembro de 1948. Disponível em: < http://unesdoc.unesco.org/images/0013/001394/139423por.pdf >. Acesso em: 03/11/2015.

${ }^{19}$ BRASIL. Constituição da República Federativa do Brasil. Preâmbulo. Diário Oficial da União, Brasília, DF, 05 out. 1988. Disponível em: http://www.planalto.gov.br/ccivil_03/Constituicao/Constituicao.htm. Acesso em: $01 / 11 / 2015$.
} 
ocidentais, em geral, estabelecem como únicos sujeitos de direito o ser humano, tendo em vista sua capacidade de agir livremente pela razão.

$\mathrm{O}$ próprio homem cria as normas para seu bem-estar e interesse pessoal. $\mathrm{O}$ art. $5^{\circ} \mathrm{da}$ lei maior ${ }^{20}$ garantiu aos homens, brasileiros ou estrangeiros residentes no país, direitos fundamentais como a inviolabilidade do direito à vida, à liberdade, à igualdade e à segurança. Excluiu-se qualquer ser não humano do rol de direitos fundamentais previstos no texto constitucional.

Embora haja um capítulo reservado ao meio ambiente na Constituição Federal de 88, que inclui os animais não humanos no rol de elementos gerais que o compõe, há de se ressaltar que o direito ambiental é antropocêntrico, vez que a tutela ao meio ambiente destinase aos interesses do homem.

Sobre os animais não humanos, o sistema constitucional brasileiro ( $\S 1^{\circ}$, VII do artigo 225 da Constituição Federal) priorizou a função ecológica da fauna e não os animais individualmente.

O atual Código Civil ainda considera os animais como coisa e os caracteriza como seres semoventes. Seu art. 82 traz a definição de bens móveis como "bens suscetíveis de movimento próprio ou de remoção por força alheia... "21.

$\mathrm{O}$ art. $1^{\circ}$ da Lei $7.705 / 92^{22}$, do Estado de São Paulo, impõe “... o emprego de métodos científicos e modernos de insensibilização, por instrumento de percussão mecânica, por processamento químico( gás CO2 ), choque elétrico (eletronarcose)...” antes do abate.

$\mathrm{O}$ art. $14, \S 9^{\circ}$ da Lei Federal $11.794^{23}$ dispõe que "Em programa de ensino, sempre que forem empregados procedimentos traumáticos, vários procedimentos poderão ser realizados num mesmo animal, desde que todos sejam executados durante a vigência de um único anestésico e que o animal seja sacrificado antes de recobrar a consciência”.

\footnotetext{
${ }^{20}$ BRASIL. Constituição da República Federativa do Brasil. Diário Oficial da União, Brasília, DF, 05 out. 1988. Disponível em: http://www.planalto.gov.br/ccivil_03/Constituicao/Constituicao.htm. Acesso em: 01/11/2015.

${ }^{21}$ BRASIL. Lei $\mathrm{n}^{\circ}$ 10.406/2002, de 10 de janeiro de 2002. Diário Oficial da República Federativa do Brasil. Brasília, DF, 11 jan. 2002. Disponível em: < http://www.planalto.gov.br/ccivil_03/leis/2002/L10406.htm>. Acesso em: 02/11/2015.

${ }^{22}$ BRASIL. Lei n. ${ }^{\circ}$ 7.705, de 19 de fevereiro de 1992. Diário Oficial da República Federativa do Brasil. São Paulo, SP, $19 \quad$ fev. $\quad 1992 . \quad$ Disponível $\quad$ em:< http://www.cda.sp.gov.br/www/legislacoes/popup.php?action=view\&idleg=22 >. Acesso em: 02/11/2015.

${ }^{23}$ BRASIL. Lei $n^{\circ}$ 11.794/98, de 08 de outubro de 2008. Diário Oficial da República Federativa do Brasil. Brasília, DF, 09 out. 2008. Disponível em: < http://www.planalto.gov.br/ccivil_03/_ato20072010/2008/lei/111794.htm>. Acesso em: 02/11/2015.
} 
A Lei $\mathrm{n}^{\mathrm{o}} 7.173 / 83^{24}$, a chamada lei dos zoológicos, regulamenta o estabelecimento e funcionamento dos zoológicos no Brasil e prevê as dimensões e instalações para fins de atendimentos das necessidades ecológicas.

Percebe-se atualmente que as lições clássicas do Direito apresentam a lei como criação do homem social. As normas refletem uma permissão geral proveniente da necessidade de preservação de cultura e costumes dos homens. É notório que a proteção do animal não humano no ordenamento jurídico brasileiro limita-se, muitas vezes, a questões de ordem econômica. Faz-se necessário um avançado para fins de uma proteção constitucional mais específica e eficaz, bem como a alteração do status jurídico do animal que hoje não passa de um objeto à disposição do homem.

\section{ANIMAIS NÃO HUMANOS: SUJEITOS DE DIREITO?}

Vive-se ainda o problema do Ser e a diferença. A diferença leva à provocação de um processo de compreensão do "todo" e, antes de qualquer análise ou organização mental, é importante que o indivíduo esteja inclinado a ultrapassar o conhecido e o habitual. Superar as diferenças requer um processo de compreensão histórico, situado em uma ordem superior, e um avanço no pensamento para campos até agora não explorados pelo indivíduo.

O que se percebe é a instalação de uma realidade que não permite ao homem se posicionar de maneira diversa da concepção de realidade originária que lhe foi imposta. Tal "realidade", oferecida ao homem em seus primórdios, lhe causa bloqueios no avanço do pensamento.

O reconhecimento dos animais não humanos como sujeito de direito ainda é muito discutido na seara jurídica pátria. Minoritária é a corrente de defensores e propagadores deste complexo entendimento. Sabe-se que o reconhecimento de direitos concretos a esses animais é uma inovação no âmbito jurídico e, declarar personalidade ao animal não humano é quebrar paradigmas e obstáculos; é abalar correntes resistentes, inclusive no Âmbito do Direito Ambiental.

\footnotetext{
${ }^{24}$ BRASIL. Lei $\mathrm{n}^{\circ}$ 7.173, de 14 de dezembro de 1983. Diário Oficial da República Federativa do Brasil. Brasília, DF, 15 dez. 1983. Disponível em: 〈http://www.planalto.gov.br/ccivil_03/leis/1980-1988/17173.htm〉. Acesso em $25 / 11 / 2015$.
} 
A incerteza quanto à natureza jurídica dos animais não humanos assola o senso comum jurídico, já que os animais não são considerados sujeitos de direito, tampouco objetos, pois há um reconhecimento de direitos, mesmo que mínimo, a esses animais.

Edna Cardozo defende a natureza jurídica dos animais como sujeitos de direito conforme se verifica a seguir:

\begin{abstract}
Um dos argumentos mais comuns para a defesa desta concepção é o de que, assim como as pessoas jurídicas ou morais possuem direitos de personalidade reconhecidos desde o momento em que registram seus atos constitutivos em órgão competente, e podem comparecer em Juízo para pleitear esses direitos, também os animais tornam-se sujeitos de direitos subjetivos por força das leis que os protegem $^{25}$.
\end{abstract}

Nos últimos anos, defensores dos direitos dos animais surgem com o objetivo de exterminar ideais especistas e lutar por uma nova visão comportamental e de valores, com inserção dos animais não humanos no mesmo patamar valorativo em que se encontram os homens.

O movimento da libertação animal está voltado à vida em sentido amplo. O que se pretende é a defesa pela vida, o extermínio da instrumentalização da vida, tendo em vista serem os animais senscientes e, portanto, sensíveis à dor e à alegria.

A visão cultural antropocêntrica imposta à sociedade é mais uma forma humana egoísta de se enxergar outras espécies. Exemplos culturais inúmeros caracterizam a exploração animal, sem contar a questão alimentar. Passeios a circos e zoológicos; visitas a aquários e espetáculos com grandes mamíferos aquáticos são exemplos mínimos que retratam a banalização da vida, frente à privação da própria natureza animal para o deleite humano.

Muitos filósofos e historiadores conferem às religiões ocidentais a exploração dos animais pelos homens. O cristianismo e o judaísmo explicam o domínio do homem em relação aos animais.

Somente no final do século XVIII que a proteção ao animal não humano passou a ocupar um espaço maior no campo da filosofia. Em 1789, Jeremy Bentham, filósofo e jurista britânico, publica o livro Introduction to Principles of Morals and Legislation ${ }^{26}$ (Introdução aos princípios da moral e da legislação), o qual ressalta que a consideração moral encontra-se

\footnotetext{
${ }^{25}$ DIAS, Edna Cardozo. Os animais como sujeitos de direito. Revista Brasileira de Direito Animal. v. 1, n. 2, pg. 65, 2006.

${ }^{26}$ BENTHAM, Jeremy; MILL, John Stuart. An introduction to the principles of morals and legislation. New York, NY: Dolphin Books, 1961.
} 
na capacidade de sentir dor ou prazer e não mais na razão e na linguagem, como antes se acreditava.

Jean-Jacques Rousseau ${ }^{27}$ já compartilhava da mesma ideia de Bentham ao afirmar que o homem jamais poderia fazer mal a outro homem ou a qualquer ser sensível, a não ser em legítima defesa. Para Rousseau, o homem deve respeitar o próximo não por ser detentor da razão, mas sim por ser capaz de sentir prazer ou dor.

O filósofo Peter Singer, autor da obra Libertação Animal ${ }^{28}$, propôs uma nova visão com o princípio moral básico da igual consideração de interesses, que protege a igualdade de todos os seres humanos com suas respectivas diferenças.

O princípio da igual consideração de interesses estabelece que a preocupação com determinado ser independe de suas características mentais, físicas, raciais, tampouco se restringe a determinadas espécies. O critério adotado por Singer para averiguação de interesses é a capacidade que determinado ser tenha de sentir alegria ou sofrer. A teoria ética de Singer busca estender o status moral dispensado ao homem aos animais e critica a tradição filosófica que valoriza a moralidade exclusivamente do homem.

Especifismo é a forma discriminatória e preconceituosa que o homem trata outras espécies, na medida em que o homem se posiciona em um patamar mais elevado em relação aos animais e os torna escravos de seu interesse.

A filosofia de $\operatorname{Regan}^{29}$ sobre os animais traz a expressão sujeitos-de-uma-vida como condição essencial à concepção de sujeito moral, logo, é portador de valor intrínseco todo o sujeito-de-uma-vida.

Pensar em animais não humanos como sujeito de direito requer desprendimento de uma visão antropocêntrica. Os que defendem os direitos dos animais se deparam com um cenário de tradições e interesses profundamente enraizados. Entretanto, a audácia e perseverança de muitos têm transformado uma história, antes imutável, com a implementação de novas formas de pensamento.

\footnotetext{
${ }^{27}$ ROUSSEAU, Jean-Jacques. O discurso sobre a origem e desigualdades entre os homens. Trad. de Paulo Neves, Porto Alegre: L\&PM pocket, 2013,pg. 19.

${ }^{28}$ SINGER, Peter. Libertação Animal. Trad. Marly Winckler, Marcelo Brandão Cipolla, São Paulo: Martins Fontes, 2013.

${ }^{29}$ REGAN, Tom. Jaulas vazias. Trad. Regina Rheda; revisão da tradução: Sônia Felipe. Porto Alegre: Lugano, 2006.
} 
A proposta inicial é desafiar o próprio "eu” e indagar: por que não observar de outra maneira? Essa mudança no modo de agir leva o homem a repensar conceitos, que se formaram ao logo da história, conceitos esses que lhes foram apresentados como únicos a serem seguidos.

\subsection{O Reconhecimento do Direito dos Animais no Direito Comparado}

Atualmente, a sociedade se depara com importantes documentos legislativos internacionais que abordam a questão do valor intrínseco existente em diversas formas de vida não humanas.

A Declaração Universal dos Direitos dos Animais ${ }^{30}$, editada pela Unesco em 27 de janeiro de 1978, embora não normativa e não cogente no direito interno, estabeleceu premissas para tutelar os direitos dos animais, ainda que muitas delas sejam de difícil concretização. O referido documento confere os seguintes direitos aos animais: à vida; à liberdade; a não submissão a maus-tratos; a viverem livres em seu ambiente natural, nos casos de animais selvagens; à duração de vida de acordo com a longevidade natural; a não exploração do animal para divertimento do homem; a não serem exibidos em espetáculos; à integralidade de seu ambiente natural; serem defendidos através de leis tal como os humanos.

O respeito à vida não humana está intimamente vinculado à ideia de reconhecimento de um valor intrínseco aos animais. A Declaração Universal dos Direitos dos Animais é uma convocação à população mundial para a mudança de hábitos e costumes.

A Áustria reconhece, no âmbito do direito civil, o Estatuto Jurídico dos Animais. O Código Civil Austríaco ${ }^{31}$, em seu art. 285, empregou conceito amplo de coisa. A inovação do art. 285-A trouxe a afirmação de que os animais não são objetos e se encontram protegidos por leis especiais.

\footnotetext{
30 ONU. Declaração Universal dos Direitos dos Animais, de 27 de janeiro de 1978. Disponível em: <http://www.apasfa.org/leis/declaracao.shtml>. Acesso em 23/11/2015.

31 AUSTRIAN. Patente de 1ten Junius 1811 JGS Sem 946/1811, alterada pela Lei Federal Gazette I. 58/2004, 77/2004, 43/2005, 51/2005, 113/06 - Código Civil Geral (ABGB). Disponível em: http://www.internet4jurists.at/gesetze/bg_abgb01.htm. Acesso em: 22/11/2015.
} 
O art. 13 do Tratado de Funcionamento da União Europeia ${ }^{32}$ dispõe que ao formular e aplicar políticas relacionadas à agricultura, à pesca, ao transporte, ao mercado interior e ao espaço, a União Europeia e os Estados-membros terão que levar em conta o bem-estar dos animais como seres sensíveis.

$\mathrm{O}$ art. 24 da Constituição ${ }^{33}$ Suíça (proteção da natureza) trouxe inovação quanto à defesa dos animais não humanos: o direito à Confederação de legislar sobre a proteção dos animais.

$\mathrm{O}$ art. 20-A da Lei Fundamental da Alemanha ${ }^{34}$ trata da proteção animal frente às gerações futuras. A República Federal da Alemanha é o primeiro país, na União Europeia, a incluir a proteção aos animais em sua Constituição.

$\mathrm{Na}$ Alemanha, o art. 90-A foi introduzido no Código Civil (BGB) ${ }^{35}$ e dispõe que os animais não são coisas e são protegidos por leis especiais. Mais a frente, o art. 903 do mesmo diploma legal, na parte de poderes do proprietário, dispõe que o proprietário de um animal, no exercício de seus poderes, deve ter em conta os preceitos especiais de sua proteção. O causador do dano é obrigado a indenizar os gastos realizados com o tratamento a que for submetido o animal vítima de violência (seção 251 BDB).

Observa-se uma preocupação maior quanto à proteção dos animais não humanos no direito comparado, com a consideração do bem-estar animal e com um especial tratamento no que tange ao reconhecimento desses animais como detentores de direitos e proteção previstas em leis especiais.

\footnotetext{
${ }^{32}$ UNIÓN EUROPEA. TRATADO DE FUNCIONAMENTO DE LA UNIÓN EUROPEA. Diario ES Oficial de la Unión Europea, de 26 de outubro de 2012. Disponível em: <http://eur-lex.europa.eu/legalcontent/ES/TXT/PDF/?uri=CELEX:12012E/TXT\&from=ES>. Acesso em 22/11/2015.

33 SWITZERLAND. Constitution. Disponível em:

<http://www.egov.ufsc.br/portal/sites/default/files/anexos/21392-21393-1-PB.html>. Acesso em: 25/11/15.

${ }^{34}$ DEUTSCHLAND. Lei Fundamental da República Federal da Alemanha. Disponível em: < https://www.btgbestellservice.de/pdf/80208000.pdf>. Acesso em: 23/11/2015.

35 GERMAN. Civil Code BGB. Disponível em: < http://www.gesetze-iminternet.de/englisch_bgb/german_civil_code.pdf >. Acesso em 25/11/2015.
} 


\section{OBRIGATORIEDADE JURÍDICA DE UMA NORMA DEFINIDORA DOS DIREITOS DOS ANIMAIS NO ORDENAMENTO JURÍDICO PÁTRIO}

O Estado brasileiro carece de uma instituição legislativa específica de proteção aos animais não humanos que estabeleça obrigações e responsabilização imediatas contra o causador de maus tratos ao animal não humano. Necessita-se de implantação de programas de proteção aos animais e de fundamentação específica para adoção de medidas protetivas. Necessária é a atuação dos operadores do direito para se extrapolar essa abstração existente hoje no ordenamento jurídico constitucional brasileiro.

A positivação da proteção dos animais, em um primeiro momento, encontra-se nas mãos do legislador. Todavia, o antropocentrismo limita a edição de normas jurídicas direcionadas à proteção efetiva desses animais, vide a não ratificação da Declaração dos Direitos dos Animais pelo Brasil, embora signatário.

Em um mundo evidentemente antropocêntrico, questões como dignidade, respeito e valor intrínseco ainda se encontram obscuros na sociedade quando discutidas no âmbito dos animais não humanos. A extensão de todo o conteúdo semântico da palavra dignidade aos animais não humanos é ainda um problema enfrentado e muito discutido entre diversos filósofos contemporâneos.

É inaceitável um país como o Brasil, em que se possui a maior biodiversidade do planeta, apresentar um ordenamento jurídico tão pobre, pode-se dizer, quase zero, em relação à proteção efetiva dos animais não humanos. $\mathrm{O}$ anseio por mudanças vem sendo propagado por anos e até a presente data o que se observa é o interesse e o prazer humano de explorar a vida animal.

Há a necessidade de se olhar a autonomia não mais com os olhos da tradição, mas sim através da autonomia prática, conforme a proposta de Wise, que amplia o conceito de autonomia e o estende aos animais não humanos, vez que os animais não humanos possuem capacidade de fazer escolhas livremente. Alguns animais são dotados de consciência, “compreendem símbolos, utilizam da linguagem para se comunicarem, possuem características similares às do homem como, por exemplo, capacidade de imitar, disfarçar, transparecer estados emocionais, dentre outras". ${ }^{36}$ Para o autor, a capacidade de livre escolha por determinados seres não humanos os insere na esfera da personalidade jurídica e, assim, a importância de abranger esses animais em uma esfera de valores morais.

${ }^{36}$ WISE, Steven M. Drawing the Line: Science and the case for Animal Rights. Cambridge: Perseus Books, 2002, p. 36. 
O que se verifica, em uma visão geral, é que a norma constitucional é abstrata e não aplicável. Clama-se por uma mudança efetiva com relação à consideração moral do animal não humano, tanto por parte dos poderes legislativo, executivo e judiciário, quanto por parte da sociedade.

\section{CONCLUSÃO}

Uma forma bastante simplista de se idealizar direitos está na ideia do conjunto de normas organizadas em um código. A bem da verdade, há normas dispensadas aos seres humanos independentemente de sua positivação.

Ao longo da história, os homens construíram e modificaram conceitos que regularam a vida em sociedade. Tais modificações se deram devido a conquistas que se realizaram em vários campos da sociedade.

Dessa feita, necessário é que ocorram também transformações quanto ao tratamento dos animais não humanos, tratamento esse ainda visto de maneira engessada em prol da satisfação do homem.

Nos primórdios da civilização humana, os animais eram vistos como coisas e sem nenhum valor intrínseco, eram instrumentalizados para atender às necessidades humanas. $\mathrm{O}$ cristianismo contribuição para essa concepção de instrumentalização do animal não humano. Ademais, diversos filósofos propagavam a ideia de que os animais eram insensíveis a dor e à alegria.

A partir do final do século XVIII filósofos fundamentadamente apresentaram teorias que revolucionaram o pensamento tradicional da época e afirmaram que os animais não humanos eram seres senscientes e, portanto, capazes de sentir dor e prazer e, ainda, possuem consciência.

Em que pese a quebra de paradigma acima apresentada, o ordenamento jurídico brasileiro ainda considera os animais como meros bens móveis, o que permite a exploração desses animais pelos seres humanos. Ora, se o ordenamento jurídico pátrio reconhece personalidade jurídica a algumas ficções jurídicas, como é o caso das pessoas jurídicas, por que não reconhecer personalidade jurídica (sujeito de direito) aos animais não humanos para, assim, pleitearem em juízo seus direitos quando violados? Nesse contexto, reconhecida a personalidade jurídica aos animais não humanos mudar-se-ia sua natureza jurídica e 
consequentemente as disposições constitucionais assumiriam uma nova roupagem quanto à efetividade dos direitos aos animais não humanos.

\section{REFERÊNCIAS}

AUSTRIAN. Patente de 1ten Junius 1811 JGS Sem 946/1811, alterada pela Lei Federal Gazette I. 58/2004, 77/2004, 43/2005, 51/2005, 113/06 - Código Civil Geral (ABGB). Disponível em: <http://www.internet4jurists.at/gesetze/bg abgb01.htm>. Acesso em: 22 nov.

2015.

BENTHAM, Jeremy; MILL, John Stuart. An introduction to the principles of morals and legislation. New York, NY: Dolphin Books, 1961.

BRASIL. Constituição da República Federativa do Brasil. Diário Oficial da União, Brasília, DF, 050 out. $1988 . \quad$ Disponível em: <http://www.planalto.gov.br/ccivil_03/Constituicao/Constituicao.htm>. Acesso em: 01 nov. 2015.

BRASIL. Lei no 5.197/67, de 03 de janeiro de 1967. Diário Oficial da República Federativa do Brasil. Brasília, DF, 03 jan. 1967. Disponível em: <http://www.planalto.gov.br/ccivil_03/LEIS/L5197.htm>. Acesso em: 02 nov. 2015.

BRASIL. Lei no 7.173, de 14 de dezembro de 1983. Diário Oficial da República Federativa do Brasil. Brasília, DF, 15 dez. 1983. Disponível em: <http://www.planalto.gov.br/ccivil_03/leis/1980-1988/17173.htm>. Acesso em 25 nov. 2015.

BRASIL. Lei n. ${ }^{\circ}$ 7.705, de 19 de fevereiro de 1992. Diário Oficial da República Federativa do Brasil. São Paulo, SP, 19 fev. 1992. Disponível em:< http://www.cda.sp.gov.br/www/legislacoes/popup.php?action=view\&idleg=22>. Acesso em: 02 nov. 2015.

BRASIL. Lei no 9.605/98, de 12 de fevereiro de 1998. Diário Oficial da República Federativa do Brasil. Brasília, DF, 13 fev. 1998. Disponível em: < http://www.planalto.gov.br/ccivil_03/LEIS/L9605.htm>. Acesso em: 10 nov. 2015.

BRASIL. Lei no 10.056/94, de janeiro de 1994. Diário Oficial da República Federativa do Brasil. Porto Alegre, POA, 10 jan. $1994 . \quad$ Disponível em: <http://www.al.rs.gov.br/legis/M010/M0100099.ASP?Hid_Tipo=TEXTO\&Hid_TodasNorma $\underline{\mathrm{s}=13809 \& \mathrm{hT} \text { Texto }=\& \text { Hid_IDNorma=13809> }}$. Acesso em: 02 nov. 2015.

BRASIL. Lei $\mathrm{n}^{\circ} 10.406 / 2002$, de 10 de janeiro de 2002. Diário Oficial da República Federativa do Brasil. Brasília, DF, 11 jan. 2002. Disponível em: < http://www.planalto.gov.br/ccivil_03/leis/2002/L10406.htm>. Acesso em: 02 nov. 2015. 
BRASIL. Lei no 10.519/02, de 17 de julho de 2002. Diário Oficial da República Federativa do Brasil. Brasília, DF, 18 jul. 2002. Disponível em: < http://www.planalto.gov.br/ccivil_03/leis/2002/L10519.htm>. Acesso em: 02 nov. 2015.

BRASIL. Lei no 11.794/98, de 08 de outubro de 2008. Diário Oficial da República Federativa do Brasil. Brasília, DF, 09 out. 2008. Disponível em: < http://www.planalto.gov.br/ccivil_03/_ato2007-2010/2008/lei/111794.htm>. Acesso em: 02 nov. 2015.

BRASIL. Resolução no 877/2008 do Conselho Federal de Medicina Veterinária, de 15 de fevereiro de 2008. Diário Oficial da República Federativa do Brasil. Brasília, DF, 19 mar. 2008. Disponível em: < http://www.cfmv.org.br/consulta/arquivos/877.pdf $>$. Acesso em: 30 nov. 2015.

BRASIL. Supremo Tribunal Federal. Recurso Extraordinário n. 153531. STF, RE 153531, Rel. Min. FRANCISCO REZEK, Relator(a) p/ Acórdão: Min. MARCO AURÉLIO, Segunda Turma, julgado em 03/06/1997, DJ 13-03-1998 PP-00013 EMENT VOL-01902-02 PP00388).

Disponível

em: $<$ http://www.stf.jus.br/portal/jurisprudencia/listarJurisprudencia.asp?s1=\%28RE+153531\%29 $\underline{\text { \&base}=\text { baseAcordaos }>}$. Acesso em: 30 nov. 2015.

BRASIL. Supremo Tribunal Federal. ADI n. 1856. STF, ADI 1856, Rel. Min. CELSO DE MELLO, Tribunal Pleno, julgado em 26/05/2011, DJe-198 DIVULG 13-10-2011 PUBLIC 14-10-2011 EMENT VOL-02607-02 PP-00275 RTJ VOL-00220- PP-00018 RT v. 101, n. 915, 2012, p. 379-413. Disponível em: <http://www.stf.jus.br/portal/jurisprudencia/listarJurisprudencia.asp?s1=\%28ADI+1856\%29

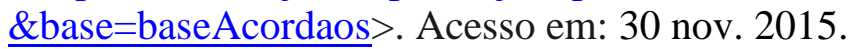

CANOTILHO, José Joaquim. O direito ao ambiente como direito subjectivo. In: A tutela jurídica do meio ambiente: presente e futuro. Boletim da Faculdade de Direito da Universidade de Coimbra - Stvdia Ivridica 81, Colloquia 13. Coimbra: Coimbra Editora, 2005.

DESCARTES, René. Discurso do método. Trad. de Paulo Neves. Porto Alegre: Coleção LPM pocket, 2015.

DEUTSCHLAND. Lei Fundamental da República Federal da Alemanha. Disponível em: <https://www.btg-bestellservice.de/pdf/80208000.pdf>. Acesso em: 23 nov. 2015.

DIAS, Edna Cardozo. Os animais como sujeitos de direito. Jus Navegandi. Disponível em: <https://jus.com.br/artigos/7667/os-animais-como-sujeitos-de-direito>. Acesso em: 20 nov. 2015.

Dignidade. In: Dicionário Aurélio On Line. Disponível em: <http://dicionariodoaurelio.com/dignidade>. Acesso em: 18 nov. 2015. 
FELIPE, Sônia T. Por uma questão de princípios: Alcance e limites da ética de Peter Singer em defesa dos animais. Florianópolis: Fundação Boiteux, 2003.

GERMAN. Civil Code BGB. Disponível em: < http://www.gesetze-iminternet.de/englisch_bgb/german_civil_code.pdf $>$. Acesso em 25 nov. 2015.

HOBBES, Thomas. Leviatã. Trad. Rosina D’Angina. São Paulo: Martin Claret, 2015.

KELSEN, Hans. Jurisdição Constitucional. Trad. Alexandre Krug, Eduardo Brandão, Maria Ermantina Galvão. São Paulo: Martins Fontes, 2003.

MOLINARO, Carlos Alberto; MEDEIROS, Fernanda Luíza Fontoura de; SARLET, Ingo Wolfgang; FENSTERSEIFER, Tiago. A dignidade da vida e os direitos fundamentais para além dos humanos: uma discussão necessária. Belo Horizonte: Fórum, 2008.

ONU. Declaração Universal dos Direitos dos Animais, de 27 de janeiro de 1978. Disponível em: <http://www.apasfa.org/leis/declaracao.shtml>. Acesso em 23 nov. 2015.

ONU. Resolução 217 A (III) da Assembleia Geral das Nações Unidas, de 10 de dezembro de 1948. Disponível em: < http://unesdoc.unesco.org/images/0013/001394/139423por.pdf>. Acesso em: 03 nov. 2015.

REGAN, Tom. Jaulas vazias. Trad. Regina Rheda; revisão da tradução: Sônia Felipe. Porto Alegre: Lugano, 2006.

ROUSSEAU, Jean-Jacques. O discurso sobre a origem e desigualdades entre os homens. Trad. de Paulo Neves, Porto Alegre: L\&PM pocket, 2013.

SINGER, Peter. Libertação animal. Trad. Marly Winckler, Marcelo Brandão Cipolla, São Paulo: Martins Fontes, 2013.

STRECK, Lênio Luiz. Jurisdição Constitucional e Hermenêutica. Rio de Janeiro: Forense, 2004.

STRECK, Lênio Luiz. Jurisdição Constitucional e Hermenêutica: Perspectivas e Possibilidades de Concretização dos Direitos Fundamentais- Sociais no Brasil. Novos Estudos Jurídicos - Volume 8 - $\mathrm{N}^{\mathrm{o}} 2$ - p.10, maio/ago. 2003.

SWITZERLAND. Constitution. Disponível em: <http://www.egov.ufsc.br/portal/sites/default/files/anexos/21392-21393-1-PB.html>. Acesso em: 25 nov. 2015. 
UNIÓN EUROPEA. TRATADO DE FUNCIONAMENTO DE LA UNIÓN EUROPEA. Diario ES Oficial de la Unión Europea, de 26 de outubro de 2012. Disponível em: <http://eurlex.europa.eu/legal-content/ES/TXT/PDF/?uri=CELEX:12012E/TXT\&from=ES>. Acesso em 22 nov. 2015.

WISE, Steven M. Drawing the Line: Science and the case for Animal Rights. Cambridge: Perseus Books, 2002. 